UDC 347.961 .9

LBC 67.76

\title{
SOCIAL-LEGAL FACTORS INFLUENCING THE EVOLUTION OF THE LATIN TYPE NOTARIAT
}

\author{
Igor A. Ostapenko \\ Pension Fund Office of the Russian Federation in Dzerzhinsky District of Volgograd, \\ Volgograd, Russian Federation
}

\begin{abstract}
Introduction: the article defines the objective factors of formation and development of the institution of notariat in a number of Western Europe countries. The functions similar to notary ones already appeared in the ancient civilizations as a kind of administrative activity. The subsequent evolution of the institute of notariat has been affected by various social-economic factors existing in a particular historical time period. Objective: to study the background and causes that led to the development of notariat as a body stabilizing the civil circulation by means of the extrajudicial form of protecting the rights and lawful interests of persons. Methods: the framework of the methodological arsenal of the article is the methods of scientific knowledge, analysis, the historical and legal method and the comparative law method which are used in it. Results: the analysis of the most important prerequisites for facilitating the formation of notary bodies in Western Europe, particularly in France and Germany, is conducted. Conclusions: in each of the countries of Western Europe, notariat had their specific features of development; the basis of such features was different social and economic processes in a particular period. At the same time, the close interaction of the national notarial systems in Western Europe led to the formation of a certain uniform system of the organization of notariat and the uniform exercise of their notarial acts, which later received the name of the Latin type notariat. In the countries which are included in the system of the Latin type notariat the specific features related to the notarial activities, which generally do not affect the current uniformity in the exercise of their notarial acts, continue to exist. The general conclusion is the characteristics of notarial activities as law enforcement ones, which are active in the stabilization of civil circulation through the pre-trial settlement of conflicts and disputes, protection of the whole complex of various property rights and interests.

Key words: notariat, civil circulation, history of notariat, Latin notariat, law, notary status.
\end{abstract}

УДК 347.961 .9

ББК 67.76

\section{СОЦИАЛЬНО-ПРАВОВЫЕ ФАКТОРЫ, ВЛИЯЮЩИЕ} НА ЭВОЛЮЦИЮ НОТАРИАТА ЛАТИНСКОГО ТИПА

\author{
Игорь Анатолиевич Остапенко \\ Управление Пенсионного фонда Российской Федерации в Дзержинском районе г. Волгограда, \\ г. Волгоград, Российская Федерация
}

Введение: в статье выявляются объективные факторы становления и развития института нотариата в ряде стран Западной Европы. Похожие на нотариальные функции возникли уже в древних цивилизациях как _ разновидности административно-хозяйственной деятельности. В последующем на эволюцию института нотариата в Западной Европе оказывали влияние различные социально-экономические факторы, существовавшие в тот или иной исторический период времени. Цель: изучить предпосылки и причины, обусловившие развитие нотариата как органа, стабилизирующего гражданский оборот посредством внесудебной формы защиты прав и законных интересов лиц. Методы: основу методологического арсенала статьи составляют использованные в ней методы научного познания, анализа, историко-правовой и сравнительно-правовой. Результаты: проводится анализ наиболее значимых предпосылок, способствовавших формированию нотариальных органов в Западной Европе, в частности во Франции и Германии. Выводы: в каждой из стран Западной Европы нотариат имел свои специфические особенности развития, основу такой специфики со- 


\section{МЕЖДУНАРОДНОЕ ПРАВО И СРАВНИТЕЛЬНОЕ ПРАВОВЕДЕНИЕ}

ставили протекающие в тот или иной период времени социально-экономические процессы. В то же время тесное взаимодействие национальных нотариальных систем в Западной Европе привело к формированию некой единой системы организации нотариата и единообразному осуществлению ими своих нотариальных действий, получившей впоследствии наименование латинский тип нотариата. В странах, которые входят в систему латинского типа нотариата, продолжают существовать специфические особенности, связанные с нотариальной деятельностью, которые в целом не влияют на сложившееся единообразие в осуществлении ими своих нотариальных действий. Обобщающим выводом является характеристика нотариальной деятельности как правоохранительной, активно проявляющая себя в стабилизации гражданского оборота посредством досудебного разрешения конфликтных ситуаций и споров, охраны целого комплекса различных имущественных прав и интересов.

Ключевые слова: нотариат, гражданский оборот, история нотариата, латинский нотариат, законодательство, статус нотариуса.

\section{Введение}

Нотариат возник в тех странах, где активно происходило развитие товарного оборота и возникшей в связи с этим потребности в содействии при заключении различных договоров, а также юридическом признании и закреплении приобретаемых прав, защите собственности, обеспечении бесспорности имущественных прав, охраны прав всех участников гражданского оборота.

\section{Нотариат в раннем Средневековье}

Традиционное возникновение нотариата восходит примерно к ІІІ в. до н. э. в республиканский период Древнего Рима в связи с наличием ряда сложившихся объективных обстоятельств: возрастающей юридической стороны расширяющегося гражданского оборота, развития системы вещных прав, обязательственных и наследственных правоотношений, проникновения в классическое римское право правовых норм завоеванных государств и формирования торгового и международного частного права (ius gentium).

Постепенно складывалась обширная юридическая практика по разрешению возникающих правовых споров, что требовало наличия подготовленных лиц в соответствующей области правоотношений и привело к возникновению профессии писарей (писцов).

Писцы стали предвестниками табеллионов в Древнем Риме [13, с. 61]. Их обязанности по сравнению с писцами древнего мира постепенно расширялись и включали в себя не только ведение книг - реестров, но и составление прошений, разного рода посланий и совершение различных сделок. Так была начата эпоха расцвета римской юриспруденции.

В указанный период времени выделились две относительно самостоятельные группы писцов: состоящие на государственной службе (scribae) и осуществлявшие свою деятельность у частных лиц, которые были или свободными людьми, «exceptores», или рабами, называвшимися «notarii».

В Древнем Риме постепенно выделяется еще одна группа лиц, занимавшихся оформлением правовых документов и сделок. Это табеллионы («tabelliones») - разряд лиц, которые, не будучи на государственной службе, были свободными людьми, занимались составлением юридических актов и судебных бумаг под контролем государства для всякого нуждающегося в них за установленное законом вознаграждение. Именно институт табеллионов, по мнению современных ученых, является прообразом нотариата [2, с. 104-120].

Сама же этимология слова «нотариус» имеет латинские корни и обозначает особые стенографические знаки, используемые в письме под диктовку, а его появление относится к 103 г. до нашей эры.

Римская западная империя пала под натиском варваров, но институт табеллионов сохранил свое существование, о чем свидетельствуют некоторые законодательные акты (например, Эдикт Ротари (643 г.), закон Лиутпранда (713-755 гг.), которые регламентировали соблюдение письменной формы для важнейших соглашений, а также определяли круг лиц, осуществлявших их составление, кроме этого указанные акты возлагали на них также различные иные правовые функции [11].

Причинами сохранения института нотариата в указанный период явились: постепен- 
И.А. Остапенко. Социально-правовые факторы, влияющие на эволюцию нотариата латинского типа

ное увеличение гражданского оборота на завоеванных варварами бывших римских территориях; увеличение количества заключаемых письменных договоров; низкий уровень развития местного права и наличие в нем изрядного количества пробелов; необходимость снижения количества спорных и незаконных имущественных операций; общая стабилизация гражданских отношений на всей территории Римской империи.

Указанные причины и потребовали участия в гражданском обороте грамотных в области права лиц - нотариусов.

В истории Западной Европы был период, когда церковь играла важнейшую роль как в духовной, так и светской жизни средневекового человека, что привело к возникновению церковного нотариата, когда функции нотариуса стали выполнять представители церкви. Причиной распространения и существования церковного нотариата стало повсеместное проникновение католицизма во все светские стороны жизни человека.

Очередной этап реформирования института нотариата связан с государственной деятельностью Карла Великого (747-814 гг.). Основной причиной такой реформы стало создание единого государства с единой правовой системой и единым источником права капитулярия, в которых была сделана попытка введения единых форм сделок с участием нотариуса на всех завоеванных территориях империи.

Немаловажным фактором осуществления реформы нотариата также стало то, что Карл Великий стал создавать светский нотариат, ограничивая духовенство в занятии нотариальной деятельностью и составлении документов по юридическим сделкам для мирских людей. Это был первый шаг к формированию новой организации нотариата, где нотариус постепенно становится государственным лицом, а не представителем духовенства [9, с. 41-45].

Сформированный при Карле Великом светский нотариат получает наибольшее развитие только на территории итальянского Средиземноморья, чему способствовали благоприятная почва, подготовленная римским правом, и наиболее развитый на соответствующей территории средневековой Европы гражданский оборот. Во Франции и Германии он просуще- ствовал недолго и уже после распада империи пришел в полный упадок [1].

Смерть короля Людовика I Благочестивого в 840 г. привела к тому, что империя распалась, а многие правовые достижения того времени канули в прошлое, в том числе достигнутый на тот момент уровень нотариального дела. Только кое-где в Италии сохранялись очаги действующего римского права. Причин тому несколько: зарождение в Болонье, Венеции, Неаполе и других городах нового класса буржуазии, развитая внешняя и внутренняя торговля, становление банковской системы. Указанные потребности гражданского оборота требовали грамотного правового оформления, а также наличия сведущих в этом лиц. Этому могли способствовать основы римского права и нотариус как лицо, способное стабилизировать возникавшие в соответствующий период гражданские отношения.

Впоследствии из итальянских земель и Средиземноморья нотариат распространяется в Европе преимущественно в тех местах, где активно развивался торговый оборот [3, c. 20]. В связи с этим средневековый итальянский нотариат стал прототипом общеевропейского нотариата и вместе с римским правом был воспринят Францией и Германией.

После образования в средневековой Европе самостоятельных государств развитие нотариата в каждом из них происходило различными темпами со своими особенностями, которые во многом зависели от существующих на тот момент различных социальных, политических и экономических факторов. Среди последних, обусловивших развитие нотариата как института, необходимого для эффективного функционирования гражданского оборота, следует отметить постепенный экономический подъем, приводивший как к усложнению видов, так и увеличению количества совершаемых сделок в средневековой Европе.

\section{Германия}

Впервые появление в Германии нотариусов итальянского типа отмечается в XIV в., они выступали в роли официальных писцов в различных присутственных местах. Сама должность нотариуса была введена до этого Карлом Великим еще в IX веке [5, с. 38]. Это 


\section{МЕЖДУНАРОДНОЕ ПРАВО И СРАВНИТЕЛЬНОЕ ПРАВОВЕДЕНИЕ}

были писцы при аббатах, епископах и графах. Первоначально их назначение осуществлял папа или император, так как принадлежащие им полномочия по общему правилу считались действительными повсюду. Позднее это уже стало правом германского императора, который реализовывал его совместно с папой [2, c. 104-120].

Проводя ретроспективный анализ исторического отрезка с IX по XV в., необходимо отметить довольно незначительную роль нотариуса в германских землях. Он воспринимался только с позиции писаря, способного лишь к фиксации ряда правовых отношений, без возложения на него каких-либо классических нотариальных функций.

Указанному обстоятельству способствовал ряд существовавших факторов: национальное воззрение на тот период германского народа на порядок совершения частных юридических сделок, где нотариусу не отводилось какого-либо значения, исторически уже сложившееся сосредоточение нотариальной функции в руках духовенства, а не светских лиц.

Кроме этого развитие нотариата тормозило «право печати» [2, с. 221]. Данным правом обладали исключительно представители дворянства.

Наличие указанного права повлекло передачу нотариальных действий различным должностным лицам, в том числе и представителям духовенства, что в итоге сделало существование самостоятельного института нотариата, по сути, излишним.

Вскоре в Германии начала ощущаться настоятельная потребность в более четкой и подробной регламентации нотариального дела, причиной тому послужил ряд политико-правовых событий.

После того как право назначения нотариусов закрепилось за императором, нотариусы могли селиться и осуществлять свою деятельность в любой области Германской империи. Позднее император делегировал право назначать нотариусов императорским чиновникам, которые со временем стали неограниченно пользоваться этим: назначение нотариусов превратилось фактически в продажу должности [15, S. 634].

Из-за отсутствия должного правового регулирования и контроля нотариусами все чаще назначались лица, которые не располагали необходимым образованием и практическими навыками. Отсутствие контроля со стороны нотариальных корпораций, избыточное число нотариусов $[17, \mathrm{~S} .230]$ и их недостаточная квалификация привели к полному расстройству нотариальной сферы.

Одновременно с этим в Германии начался процесс экономического и хозяйственного подъема, что привело к увеличению количества видов заключаемых гражданских договоров, в связи с чем возникла потребность в грамотном юридическом сопровождении заключаемых сделок.

Наличие указанных противоречий вызвало потребность в реформировании и развитии нотариата на новом, более высоком уровне. В указанных обстоятельствах для нормализации ситуации в нотариальной сфере на рейхстаге в Кельне 18 октября 1512 г. император Максимилиан I принял Имперское положение о нотариате (Reichsnotariatsordnung). Это был первый кодифицированный акт, регулировавший осуществление нотариальной деятельности на всей территории империи.

Впервые в Германии в ст. 15 RNO нотариус определялся как «служитель общему благу, который выполнял необходимую и полезную службу» [18, S. 205].

Историческая особенность Германии в виде ее обособленных земель привела к тому, что в XIX в. сложились три разные модели нотариата: французская модель, где нотариус был независимым; прусская, где юстиц-комиссар находился на государственной службе, был и адвокатом, и нотариусом; государственная, где нотариальные функции осуществлялись судебными чиновниками [6, с. 33].

В 1933 г. к власти пришли национал-социалисты, которые одним из правовых направлений в своей деятельности проводили унификацию существующей нотариальной системы. В основу процесса унификации был положен принцип фюрерства как модель выстраивания системы нотариальных органов. В результате нотариусы были лишены властных полномочий, а институт нотариата представлялся в качестве государственного органа, подчинявшегося исключительно государству и государственным интересам [7]. 
Впоследствии в Имперском положении о нотариате 1937 г. нотариус был определен как правозащитник в сфере профилактического судопроизводства.

Легальное закрепление термина «нотариат» в Германии произошло в 1952 г. в «Постановлении об организации и деятельности государственного нотариата ГДР». В данном акте нотариат определялся как орган, осуществляющий правосудие, оформляющий гражданские правоотношения, придавая им законность на всей территории государства, укрепляя демократические принципы [16, S. 1288].

В 1961 г. в ФРГ было принято Федеральное положение о нотариате, которое частично действует по настоящее время, где нотариат определен как «публичная должность для засвидетельствования юридически значимых актов и иных задач в области предварительного правосудия» [12].

В последующем принимались различные нормативные правовые акты, которые вносили изменения или дополняли указанное положение в духе того времени (закон «Об установлении обязательной формы документации» 1969 г., закон ГДР «О нотариате» 1976 г., положение «О частнопрактикующих нотариусах» 1990 г., закон «Об адвокатуре» 1990 г. и др.) $[10$, с. 50]. Так, указанные нормативные акты актуализировали компетенцию нотариуса в обеспечении гражданского оборота посредством детального закрепления функций нотариата по удостоверению и выдаче свидетельств (по гражданским договорам, брачным договорам, наследованию, внесению в торговый реестр юридических лиц и др.), исполнительным документам, предоставлению консультаций и т. д.

\section{Франция}

Реципированный в XII в. итальянский нотариат во Франции претерпел существенные изменения, в результате он стал отличаться как от нотариата Италии, так и от средневековой Германии.

В XII в. совершение официальных актов было совмещено с выполнением судебных функций, реализуемых как единолично, так и коллегиально. В связи с этим нотариальные и судебные акты обладали единой силой и зна- чением, исполнялись непосредственно, без дополнительного гражданского судопроизводства, что порой делало деятельность нотариусов во многих отношениях конкурирующей с деятельностью суда. В целях устранения такой правовой коллизии требовалось проведение как нотариальной, так и судебной реформы.

Первую реформу французского нотариата осуществил Людовик IX, учредивший в 1270 г. институт из 60 нотариусов, которые в своей деятельности не находились в зависимости от суда, и тем самым положивший начало отделению суда от нотариата, «спорной юрисдикции от бесспорной» [1].

В последующем большое влияние на развитие нотариального дела имел указ Филиппа Красивого 1304 г., которым наряду с процедурными моментами по оформлению нотариальных актов был предусмотрен особый порядок назначения нотариусов - они утверждались в этом звании королем. В 1437, 1539 и 1541 гг. были приняты королевские ордонансы, подтверждавшие распоряжение 1304 года.

Причина, обусловившая проведение соответствующей реформы нотариата, состояла в том, что при Филиппе Красивом велись военные действия, способствовавшие присоединению новых земель, что в результате привело к большим военным расходам, которые стали покрываться за счет введения новых налогов, часть последних стала взиматься с ряда гражданско-правовых сделок и завещаний. Договоры и завещания по королевскому указу 1304 г. вносились в специальный реестр вместе с информацией о размере сбора за каждое выполненное нотариальное действие, так нотариусы как государственные служащие пополняли истощенную военными действиями казну.

В 1791 г. закон, принятый Конституционным собранием, лишил многих лиц права назначения нотариусов, устранил наследственность и возможность приобретения нотариальных должностей, объединил всех нотариусов под общим наименованием «notaires publics», ограничив их число [4, с. 17].

Современный облик нотариата сложился во Франции только в начале XIX века. Причиной тому послужил во многих отношениях прогрессивный нормативный акт «Закон о принципах организации нотариата» 1803 г., вошедший в историю как Закон от 25 Вантоза 


\section{МЕЖДУНАРОДНОЕ ПРАВО И СРАВНИТЕЛЬНОЕ ПРАВОВЕДЕНИЕ}

XI г. (от 16 марта 1803 г.) [14]. Благодаря ему и была создана впоследствии сама модель латинского нотариата ${ }^{1}$.

Стоит также отметить, что соответствующий акт не утратил своей юридической силы и по сей день, кроме того, он явился юридическим образцом для других законодательных актов, регулировавших нотариальную деятельность не только в Европе, но и во многих других государствах [3, с. 20].

После окончания Второй мировой войны начинается процесс восстановления различных сторон жизнедеятельности государства и общества. В условиях послевоенного времени восстанавливается работа прежних законов, принимаются новые нормативные акты, в том числе регулирующие нотариальную деятельность, соответствующую реалиям того времени. Так, 2 ноября 1945 г. принимается Ордонанс № 45-2590 «О статусе нотариата» ${ }^{2}$. Указанный ордонанс, как и закон Вантоза, действует и по настоящее время.

В каждой из стран Западной Европы нотариат имел свои специфические особенности становления и развития, основу такой специфики составили различные социально-экономические причины.

Во Франции исторической особенностью нотариата стало разделение нотариата и суда. Указанные органы выполняли присущие только им формы защиты права. Нотариальные акты были равнозначны судебному решению и обязательны для исполнения.

В Германии ситуация была полностью противоположной: нотариальные действия могли быть совершены и нотариусами, и судьями. Германский нотариус подчинялся судебным органам, что ограничивало его компетенцию. Это не были люди свободной профессии, как во Франции, потому что они являлись государственными служащими и получали жалованье из казны государства.

\section{Выводы}

В целом, характеризуя исторические предпосылки и процесс правового развития нотариата в зарубежных странах, можно выделить некоторые значимые факторы:

- история нотариата достаточно длительна и имеет свои предпосылки и закономернос- ти развития. Локализацией наиболее активных процессов становления нотариата в Европе стали такие страны, как Италия, а в более поздний период Франция и Германия;

- социохозяйственная потребность в формировании института нотариата обусловлена активным ведением торговой деятельности и возникла в первую очередь в странах, проявлявших такую активность;

- на основе проведенного темпорального анализа развития нотариата можно утверждать, что неотъемлемой характеристикой нотариальной деятельности является реализуемая в ходе ее осуществления правоохранительная функция, активно проявляющая себя в стабилизации гражданского оборота посредством досудебного разрешения конфликтных ситуаций и споров, охраны целого комплекса различных имущественных прав и законных интересов;

- важнейшими предпосылками увеличения количества нотариусов и возрастания роли нотариата являются усложняющиеся общественные отношения и хозяйственные связи, увеличение количества сделок, в частности связанных с недвижимостью, а также защитой права собственности;

- помимо вышеуказанных социально-экономических факторов причинами прогресса либо регресса нотариата являются проводимые политико-правовые преобразования государственных деятелей, военные действия, уровень реципированности римского права в государстве и др.;

- уровень развития нотариата и его востребованность обществом являются своеобразным зеркальным отражением уровня развития самого общества и его правовых потребностей, в связи с чем нотариат всегда выполняет актуальные для своего времени правовые функции на каждом этапе развития общества и государства;

- в каждой из стран Западной Европы нотариат имел свои особенности становления и развития, но тесное взаимодействие национальных нотариальных систем в Западной Европе привело к формированию некой единой системы организации нотариата и единообразному осуществлению ими нотариальных действий, получившей впоследствии наименование «латинский тип нотариата»; 
И.А. Остапенко. Социально-правовые факторы, влияющие на эволюцию нотариата латинского типа

- нотариусы стран, которые входят в единую систему нотариата латинского типа, осуществляют свою деятельность в рамках предоставленной им национальным законодателем компетенции, а взаимодействие между ними осуществляется на основе норм международного частного права государства.

\section{ПРИМЕЧАНИЯ}

1 Латинский тип нотариата, или латинский нотариат, - система организации нотариальной деятельности, при которой нотариусы, оставаясь лицами свободной профессии, осуществляют свои функции как представители государства. Указание на латынь связано с римским правом, послужившим основой для его возникновения.

2 О действии и содержании указанного нормативного акта см. подробнее. URL: http://www. paris.notaires.fr/sites/default/files/plaquette chambre_2013_traduction_russe_ru.pdf(дата обращения: 09.03.2017).

\section{СПИСОК ЛИТЕРАТУРЫ}

1. Афанасьева, Е. А. Некоторые тенденции эволюции нотариата в России и мире во второй половине XIX века / Е. А. Афанасьева // История государства и права. - 2015. - № 3. - С. 18-24.

2. Ляпидевский, Н. История нотариата / Н. Ляпидевский. - М. : Университетская тип. (Катков и Ко), 1857. $-321 \mathrm{c}$.

3. Мизинцев, Е. Н. Организационно-правовые основы нотариата в Российской Федерации и зарубежных странах (сравнительно-правовое исследование) : автореф. дис. ... канд. юрид. наук / Мизинцев Евгений Николаевич. - М., 2012. - 32 с.

4. Нотариат в гражданском обороте: в России и за рубежом / под ред. А. О. Иншаковой. - М. : Юрлитинформ, 2017. - 176 с.

5. Пиепу, Ж.-Ф. Профессиональное нотариальное право / Ж.-Ф. Пиепу, Ж. Ягр. - М. : Юристь, 2001. $-224 \mathrm{c}$.

6. Пожарская, Ю. В. Понятие нотариата и оценка его роли в германской правовой системе / Ю. В. Пожарская // Право и государство: теория и практика. - 2012. - № 9. - С. 33-34.

7. Пожарская, Ю. В. Понятие и роль нотариата в российской и германской правовых системах /Ю. В. Пожарская // Современный юрист. - 2013. № 2 (3). - С. 36-43.

8. Пожарская, Ю. В. Процесс развития нотариального законодательства России и Германии в
ХХ веке / Ю. В. Пожарская // Ученые записки РГСУ. - 2011. - № 5 (93). - С. 146-151.

9. Правовые основы нотариальной деятельности в Российской Федерации / под ред. Е. А. Борисовой. - М. : Юстицинформ, 2016. - 480 с.

10. Райман, В. Устройство немецкого нотариата / В. Райман // Нотариальный вестникъ. - 2004. № 8. - С. 50-56.

11. Смеян, Л. С. Учебник по нотариату в Украине: нотариат Украины / Л. С. Смеян, Ю. В. Никитин, П. Г. Хоменко. - Электрон. текстовые дан. Режим доступа: http://pravo-ukraine.org.ua/resyrsi/ biblioteka/notariat-ukrainy/uchebnik-po-notariatuukrainy/8422-vozniknovenie-i-razvitie-notariata-kakpravovogo-instituta (дата обращения: 01.03.2017). Загл. с экрана.

12. Федеральное положение о нотариате Германии от 24 февр. 1961 г. - Электрон. текстовые дан. Режим доступа: notiss.ru/usrimg/gervany_notary.pdf (дата обращения: 01.02.2017). - Загл. с экрана.

13. Фемилиди, А. М. Пособие к изучению русского нотариального права / А. М. Фемилиди. СПб. : Издание Я.А. Канторовича, 1902. - 260 с.

14. Швахтген, А. Деятельность нотариуса на благо гражданского общества / А. Швахтген // Нотариальный вестникъ. - 2002. - № 9. - С. 21-26.

15. Bresslau, H. Handbuch der Urkundenlehre für Deutschland und Italien / H. Bresslau. - Bd. 1, Aufl. 1. Leipzig, 1912. - $993 \mathrm{~S}$.

16. Das Gesetz «die staatliche notare DDR». Gesetzblatt teil I Nr. 105. - Berlin. Ausgabetag: 24. November, 1956. - S. 1288.

17. Neschwara, C. Geschichte des osterreichischen Notariats / C. Neschwara. - Wien, 1996. - Bd. I : Vom Spätmitelalter bis zu Jahr 1850. - S. 230.

18. Reichsnotariatsordnung 28.08 .1512 // Schubert, W. Geschichte des Notariats und Notariatsrechts in Deutschlahd / W. Schubert. - BadenBaden, 2009. - S. 205.

\section{REFERENCES}

1. Afanasyeva E.A. Nekotorye tendentsii evolyutsii notariata $\mathrm{v}$ Rossii i mire vo vtoroy polovine XIX veka [Some Tendencies in the Evolution of the Notarial System in Russia and Abroad in the Second Half of the $19^{\text {th }}$ Century]. Istoriya gosudarstva i prava, 2015, no. 3, pp. 18-24.

2. Lyapidevskiy N. Istoriya notariata [History of the Notary]. Moscow, Universitetskaya tip. (Katkov i Ko) Publ., 1857. 321 p.

3. Mizintsev E. N. Organizatsionno-pravovye osnovy notariata $v$ Rossiyskoy Federatsii $i$ zarubezhnykh stranakh (sravnitelno-pravovoe issledovanie): avtoref. dis. ... kand. yurid. nauk 


\section{МЕЖДУНАРОДНОЕ ПРАВО И СРАВНИТЕЛЬНОЕ ПРАВОВЕДЕНИЕ}

[Organizational and Legal Foundations of the Notarial System in the Russian Federation and Foreign Countries (Comparative Legal Research). Cand. jurid. sci. abs. diss.]. Moscow, 2012. 32 p.

4. Inshakova A.O., ed. Notariat v grazhdanskom oborote: $v$ Rossii i za rubezhom [The Notarial System in Civil Circulation: Russian and Foreign Experience]. Moscow, Yurlitinform Publ., 2017. 176 p.

5. Piepu Zh.-F., Yagr Zh. Professionalnoe notarialnoe pravo [Professional Notarial Law]. Moscow, Yurist Publ., 2001. 224 p.

6. Pozharskaya Yu.V. Ponyatie notariata i otsenka ego roli v germanskoy pravovoy sisteme [The Concept of Notarial System and Assessment of Its Role in the German Legal System]. Pravo i gosudarstvo: teoriya $i$ praktika, 2012, no. 9, pp. 33-34.

7. Pozharskaya Yu.V. Ponyatie i rol notariata v rossiyskoy i germanskoy pravovykh sistemakh [The Concept and Role of the Notarial System in the Russian and German Legal Systems]. Sovremennyy yurist, 2013, no. 2 (3), pp. 36-43.

8. Pozharskaya Yu.V. Protsess razvitiya notarialnogo zakonodatelstva Rossii i Germanii v XX veke [The Process of Notarial Legislation Development in Russia and in Germany in the $20^{\text {th }}$ Century]. Uchenye zapiski RGSU, 2011, no. 5 (93), pp. 146-151.

9. Borisova E.A., ed. Pravovye osnovy notarialnoy deyatelnosti $v$ Rossiyskoy Federatsii [Legal Basis for Notarial Activities in the Russian Federation]. Moscow, Yustitsinform Publ., 2016. 480 p.

10. Rayman V. Ustroystvo nemetskogo notariata [The Organization of the German Notarial System]. Notarialnyy vestnik, 2004, no. 8, pp. 50-56.
11. Smeyan L.S., Nikitin Yu.V., Khomenko P.G. Uchebnik po notariatu v Ukraine: notariat Ukrainy [Textbook on Notaries in Ukraine: Notary of Ukraine]. URL: http://pravo-ukraine.org.ua/resyrsi/biblioteka/ notariat-ukrainy/uchebnik-po-notariatu-ukrainy/8422vozniknovenie-i-razvitie-notariata-kak-pravovogoinstituta. (accessed March 1, 2017).

12. Federalnoe polozhenie o notariate Germanii ot 24 fevr. $1961 \mathrm{~g}$. [The Federal Regulation on the Notary of Germany of February 24, 1961]. URL: notiss.ru/usrimg/gervany_notary.pdf. (accessed February 1, 2017).

13. Femilidi A.M. Posobie k izucheniyu russkogo notarialnogo prava [The Manual for the Study of Russian Notarial Law]. Saint Petersburg, Izdanie Ya.A. Kantorovicha, 1902. 260 p.

14. Shvakhtgen A. Deyatelnost notariusa na blago grazhdanskogo obshchestva [Notary's Activity for the Benefit of Civil Society]. Notarialnyy vestnik, 2002, no. 9, pp. 21-26.

15. Bresslau H. Handbuch der Urkundenlehre für Deutschland und Italien. Leipzig, 1912, Bd. 1, Aufl. 1.993 p.

16. Das Gesetz "die staatliche notare DDR». Gesetzblatt teil I Nr. 105. Berlin, Ausgabetag, 24. November, 1956. p. 1288.

17. Neschwara C. Geschichte des osterreichischen Notariats. Wien, 1996. Bd. I : Vom Spätmitelalter bis zu Jahr 1850. 230 p.

18. Reichsnotariatsordnung 28.08.1512. Schubert $W$. Geschichte des Notariats und Notariatsrechts in Deutschlahd. Baden-Baden, 2009, p. 205.

\section{Information about the Author}

Igor A. Ostapenko, Lead Specialist - Expert (Legal Advisor), Pension Fund Office of the Russian Federation in Dzerzhinsky District of Volgograd, Respublikanskaya St., 17, 400075 Volgograd, Russian Federation, igorostapenko120983@yandex.ru.

\section{Информация об авторе}

Игорь Анатолиевич Остапенко, ведущий специалист-эксперт (юрисконсульт), Управление Пенсионного фонда Российской Федерации в Дзержинском районе г. Волгограда, ул. Республиканская, 17, 400075 г. Волгоград, Российская Федерация, igorostapenko120983@yandex.ru. 